\title{
To sea or not to sea: a brief review on salmon migration evolution
}

\author{
KOJI MAEKAWA, and SHIGERU NAKANO \\ Field Science Center for Northern Biosphere, Hokkaido University, N9 W9 Sapporo 060-8589, Japan \\ (mkoji@fsc.hokudai.ac.jp)
}

SUMMARY: Since many salmonid species have the alternative life history strategies, they provide us a good opportunity to solve such a riddle. In a model, the anadromous life history of salmon may not be an evolutionarily stable state. If the gain in fitness from staying in a river exceeds the fitness from the sea, the fluvial life history can occur or vice versa. Some data may support these predictions. The relative reproductive success of migratory and fluvial females has latitudinal variation (so called geocline); the latter will be higher at the southern limits of the ranges, and conversely, the former will have higher fitness at the northern part, probably supporting the food availability hypothesis.

\section{KEY WORDS: body size, latitude, migration evolution, Salvelinus malma, S. leucomaenis}

\section{INTRODUCTION}

Many animal species migrate long distances for feeding or breeding purposes and the points to which they return are very precise and the degree of return is high. ${ }^{1,2,3)}$ Such obligatory migrations should evolve when they maximize the expected lifetime reproductive success of individuals., ${ }^{2,45}$ In many species or populations, however, alternative life histories occur and some individuals migrate while others do not. This is especially common within salmonid fishes where both anadromous and fluvial populations or individuals are found. ${ }^{6,7,8,9, \text { but see }}{ }^{10)}$ (see Table 1)

The evolution of such alternative life history tactics, anadromy versus fluvial, represents an important bifurcation in the migration evolution of these species. However, scant information exists on their evolution. ${ }^{\text {but sec } 16,17,18,19,20)}$

We review why fluvial forms of salmonids evolve or are maintained in anadromous salmonid fishes through natural selection. We will examine the evolution from anadromous to fluvial forms (or vice versa) over the range of environmental conditions encountered throughout the species' distribution.

\section{PHYLOGENETIC DISTRIBUTION OF FLUVIAL AND ANADROMOUS LIFE HISTORIES AMONG SALMONIDS}

The variable patterns of migration and reproduction are usually interpreted in the context of a freshwater origin for salmonids. ${ }^{10 \text {, but see } 21)}$ From the genetic and morphological points of view, the phylogeny of at least salmonid genera and species suggests that primitive salmonids are restricted to freshwater (genus
Table 1. Glossary of alternative life histories in salmonid fishes e.g.,8, 9,11,12,13,14,15, 27)

Anadromy: an individual or population which spend their lives in the sea and migrate to freshwater to breed.

Migratory: an individual which migrates to the sea from the natal river.

Mature parr: an individual that does not migrate to the sea and remains within the river. In a population of some anadromous species, a part of males do not migrate to sea and remain the natal river to mature but almost all females migrate. They precociously mature at small body size, relative to the migratory ones.

Land-locked: an individual or population that remains in freshwater, physically prevented from anadromy by a barrier.

Fluvial: an individual or population that remain within their river without physical barrier (such as a water fall) to complete their life cycle.

Brachymystax and most $\left.\mathrm{Hucho}^{22}\right)$ ) while the more advanced genera (Oncorhynchus, Salmo and Salvelinus) contain sea-run species. ${ }^{23,24, \text { but sec } 10,21)}$ This trend is further reinforced in Oncorhynchus, where the most advanced species (Pacific salmon, $O$. keta and $O$. gorbuscha) become increasingly anadromous in life history. All individuals of these two species migrate downstream to the ocean immediately after emergence. By contrast, most species of Salvelinus and Salmo, and some species of Oncorhynchus, reside in streams one year or more after emergence and then go to sea. If salmonid genera and species would be derived from a freshwater salmonid-like fish, ${ }^{8,23}$ but sec 10,21 ) salmonid fishes may have evolved to live progressively more of their lives in the sea. On the other hand, most species maintain the alternative fluvial and anadromous life histories either across populations or individuals within a 
Tbale 2. Occurrence of anadromy, landlocked and fluvial populations within each species of salmon and trout.

\begin{tabular}{lcccccc}
\hline & Anadromous & \multicolumn{3}{c}{ Landlocked } & Fluvial & Reference \\
\cline { 2 - 5 } Brachimystax lenok & & river & lake & lake-stream & & \\
Hucho hucho & 0 & 0 & 0 & 0 & ++ & unpublished \\
Hucho perryi & - & 0 & 0 & 0 & ++ & 22,23 \\
Salvelinus namaycush & 0 & 0 & + & + & + & $22,23,31$ \\
S. alpinus & + & + & + & + & 0 & 32 \\
S. malma & + & + & + & + & + & 33 \\
S. leucomaenis & + & + & + & + & + & 34 \\
S. fontinalis & + & + & + & + & + & 14,35 \\
Salmo trutta & + & + & - & + & + & 36 \\
S. salar & + & + & 0 & + & + & 15 \\
Oncorhynchus mykiss & + & + & + & + & + & 9,15 \\
O. masou & + & + & + & + & + & 37 \\
O.tshawytscha & + & 0 & 0 & 0 & - & 37 \\
O. Kisutch & + & 0 & 0 & - & 0 & 37 \\
O. nerka & + & 0 & + & + & 0 & 37 \\
O. keta & + & 0 & 0 & 0 & 0 & 37 \\
O. gorbuscha & + & 0 & 0 & 0 & 0 & 37 \\
\hline
\end{tabular}

$+:$ common, -: rare, 0 : none

population. Table 2 summarizes current knowledge about the occurrence of anadromy, landlocked and fluvial populations among salmonid species. This suggests that anadromy (or migration toward sea) may not be stable in at least salmonid fishes.

\section{THEORY FOR THE EVOLUTION OF ANADROMOUS LIFE HISTORIES IN SALMONIDS}

Why do salmonids evolve anadromous life histories? Northcote ${ }^{25}$ has summarized the various strategies for freshwater fish migrations, and the reasons given in his review could easily apply to fish migrations in general, whether it be in fresh water, sea water or movements between the two. He suggests that fish migration has evolved (1) to optimize feeding, (2) to avoid unfavorable conditions, (3) to enhance reproductive success and (4) possibly to promote

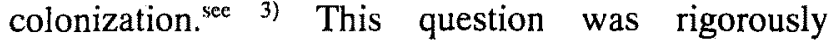
modeled by Gross $^{4}$ in terms of the relative fitness advantages from river and ocean habitats in diadromous life histories. Harada ${ }^{26)}$ modified the model of Gross to a more general formula, although both authors ended up with the same prediction. We consider only the anadromous evolution of salmonid fishes. $^{\text {see }}{ }^{27)}$ Let 1 and $b$ be the probability of an individual surviving to reproduction and its fecundity, respectively. In this case, the expectation of reproductive success is $l b$. If reproductive success of female is proportional to their body size,

$$
\begin{gathered}
l_{N A}=e^{-u_{I} T} ; b_{N A}=e^{g_{1} T} \\
l_{A}=e^{-\left(u_{1} t_{1}+u_{2} t_{2}+u_{m} t_{m}\right) T} ; b_{A}=e^{\left(g_{1} t_{1}+g_{2} t_{2}+g_{g u} t_{m}\right) T}
\end{gathered}
$$

where $u$ is instantaneous mortality; $g$ is instantaneous growth rate; the subscripts " $A$ " and " $N A$ " mean anadromous and non-anadromous (resident) form, respectively, and the subscripts " 1 ", and " 2 " and " $m$ " mean freshwater habitat, ocean habitat and migrating period, respectively; $t$ is the proportion of time $\left(t_{1}+t_{2}+t_{m}=1\right)$; $\mathrm{T}$ is age at maturity. For the evolution of anadromy, the expected reproductive success of the anadromous form $l_{\mathrm{A}} b_{\mathrm{A}}$ must be higher than that of the resident form $l_{N A} b_{N A}$. Substituting above equations, the condition for the evolution of anadromy $\left(l_{N A} b_{N A}<l_{A} b_{A}\right)$ becomes

$$
\left[\left(g_{2}-u_{2}\right) t_{2}+\left(g_{m}-u_{m}\right) t_{m}\right] /\left[t_{2}+t_{m}\right]>g_{1}-u_{1}
$$

This implies that average of the difference between the growth rate and mortality of the anadromous form must exceed that of the resident form. During migration, the growth rate usually decreases $\left(g_{m}<g_{1}\right)$ and the mortality usually increases $\left(u_{m}>u_{1}\right)$. Furthermore, survivorship in anadromous species is generally higher in rivers than in the sea. If these conditions are satisfied, eqn 1 becomes 


$$
g_{2}<g_{1}
$$

That is, the growth rate (and as a consequence, body size at maturity) may be a key variable in salmon

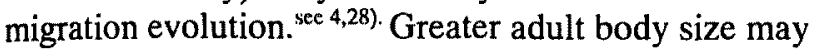
be an important determinant of reproductive success in salmonid fishes that compete strongly for mates. ${ }^{29)}$.

In contrast, if $g_{2} \quad g_{1}$, eqn 1 can not be realized for the same conditions $\left(g_{m}<g_{1}, u_{m}>u_{1}\right.$ and $\left.u_{2}>u_{1}\right)$. In this case, the anadromous migration does not evolve. The presence of an alternative life history in anadromous salmonid species ${ }^{4}$, may be attribute to the environmental condition in which the productivity of the freshwater habitat is higher than that of the sea.

Considering the importance of food intake for body growth and the contribution of growth to fitness through the decreased mortality and increased fecundity, Gross et al ${ }^{28)}$ proposed a food availability hypothesis (FAH) which predicts that the relative productivity of oceans and freshwater habitats changes with latitude and anadromy will evolve when the ocean productivity is greater than that in the neighboring freshwater habitats. In the northern hemisphere, ocean productivity (primary productivity) relative to the neighboring freshwater habitats decreases gradually from north to south. ${ }^{28)}$ Particularly, the primary productivity of the Bering Sea and Okhotsk Sea may be relatively high. ${ }^{29)}$ Since food availability for individuals strongly affects their growth rate or body size at maturity, we predict that a latitudinal trend occurs in their body size at maturity and/or growth rate, reflecting the difference of food availability between ocean and freshwater habitats with latitude. This FAH may be applicable to the evolution of salmon migration, although not applicable to that of the other diadromous fishes (anadromous other than salmonids, catadromous and amphidromous) because improving the survival of the vulnerable egg and larval stages may represent a significant contribution to lifetime reproductive success rather than the adult size. ${ }^{3()}$

\section{GEOGRAPHIC DISTRIBUTION OF FLUVIAL AND ANADROMOUS LIFE HISTORIES: A TEST OF THE THEORY}

Some salmonid species, such as Dolly Varden, ${ }^{34.35 \text { ) }}$ Arctic charr, ${ }^{33)}$ Brook charr, ${ }^{36)}$ white spotted charr, ${ }^{14,35)}$ brown trout ${ }^{38)}$ and masu salmon, ${ }^{39)}$ have a common characteristic that all individuals of populations near the southern limits of their distribution are fluvial while all individuals of northern populations are anadromous, excluding landlocked population, ${ }^{12,14,35)}$ although not all populations of Salmo salar and S. trutta may be anadromous there. Thorpe, personal communication)

Particularly good data sets are available for the white-spotted charr and Dolly Varden. ${ }^{\text {see27) }}$ Both species perform relatively short distance migrations in the ocean and also all populations at the southern limits of their distribution are fluvial in the Japanese archipelago. ${ }^{14,35,41,42)}$ For these two species, adult body sizes of fluvial and anadromous life histories are available to test the theory of Gross ${ }^{4}$ ) that anadromy is expected when it provides greater or higher fitness advantage than does the fluvial life history. As shown in Figure $1^{27)}$, the body size at maturity of anadromous individuals in the northern part of their range is greater than that of fluvial individuals in the southern part, suggesting that the former individuals have potentially much higher fitness than do the latter. This
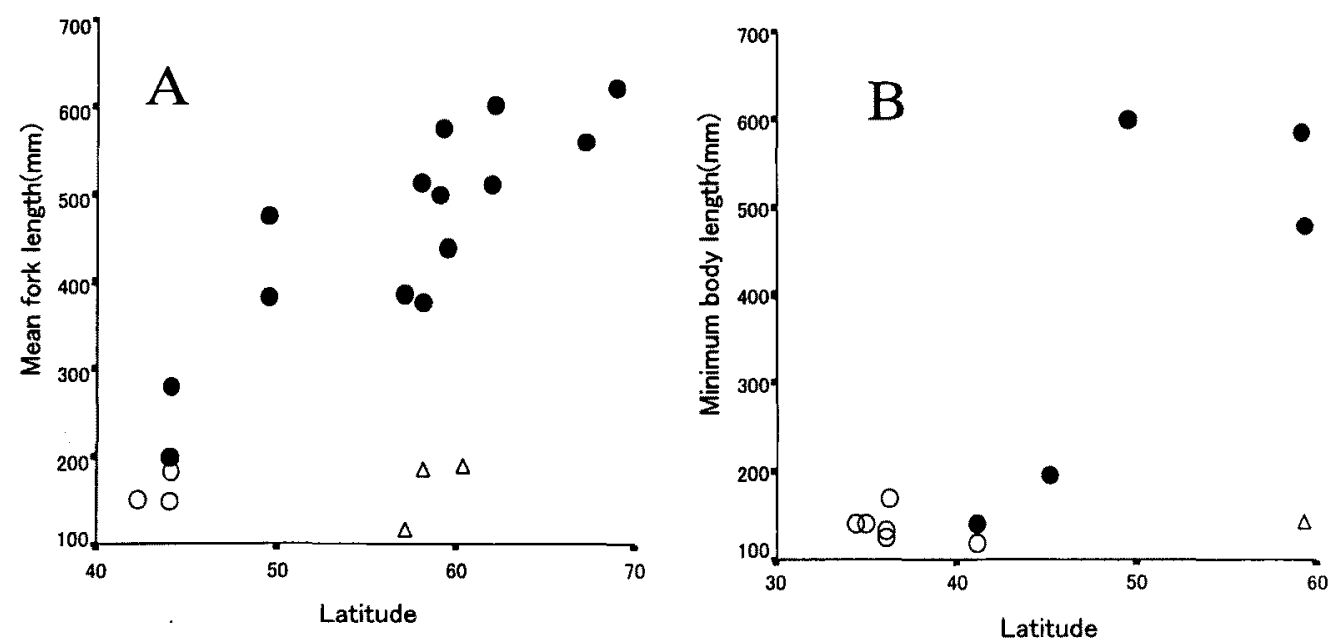

Fig. 1 The relationship between body size at maturation, latitude, and life history for population of Dolly Varden, Salvelinus malma

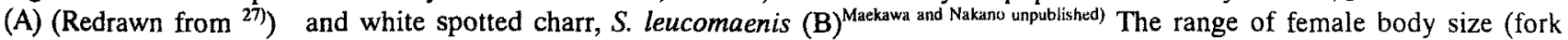
length) in each population is shown for each population across the latitudinal distribution of each species in Japan and North America. Solid circles, open circles and triangles indicate anadromous, fluvial and land-locked populations, respectively. 
is particularly true in females, because their body size is strongly correlated with fecundity. ${ }^{43)}$ In the southern range of their distributions of both species, however, body sizes of anadromous and fluvial forms appear to be similar or be slightly larger in the former (Fig. 1). Considering the high survival rate of the fluvial form relative to the anadromous one, this suggests that the fitness of both forms are almost same in this part of their range and also that the advantage for the fluvial form (including the land-locked population) exceeds that for anadromy at the southern limit of their distribution. Thus, under the assumptions that ocean productivity relative to the neighboring freshwater productivity decreases from north to south and growth rate may be proportional to adult body size, the observations support our predictions derived from the model and the FAH in data sets of both species. Therefore, food availability in freshwater may exceed that in the sea near the southern end of the distribution of charrs. Additionally, as expected by the model, ${ }^{4)}$ increased times for migration and decreased survivorship during migration from river to the sea will also become costs in evolution of anadromy. Because they always live upstream around the southern limits of salmonid distribution, ${ }^{40)}$ the more southern is their habitat, the higher the elevation of their thermal habitat and the more the migration risk will increase. ${ }^{35)}$

Here, we note that there is no significant relationship between the body size of fluvial and landlocked charr and latitude. The threshold size sensu $44,45,46,47,48)$ or minimum size, for being mature female parr (stream resident female) may not change with

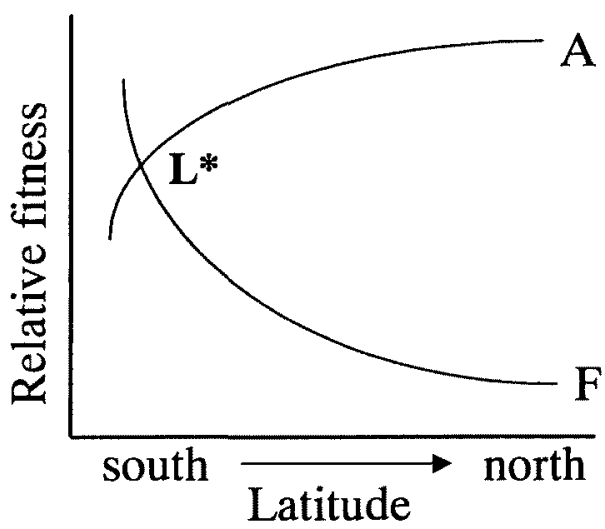

Fig. 2 The hypothetical relationship between fitness of anadromous (A) and fluvial (F) populations of salmonids and their latitude. In the southern limits of their ranges, the fitness of the fluvial life history exceeds that of the anadromous life history. In the northern part, the reverse holds true. Near L*, the relative fitness of the two life histories is approximately equal, suggesting the coexistence of both life histories. latitude. In contrast, the threshold size for being a smolt may change with latitude, and a crude relationship exists between the latitude of a river and the mean age of its smolts. ${ }^{49,50)}$ This suggests that the growth rate of fluvial and landlocked charr may be higher in the southern part of the distribution than that in northern part. ${ }^{27)} \quad$ Powe $^{18)}$ and Berg ${ }^{19)}$ suggested the importance of low growth rate and low temperature of rivers in the formation of non-anadromous Atlantic salmon.

Considering the distribution of the fluvial and anadromous forms throughout their range (Fig. 1), we suggest that the potential fitness of the fluvial life history, especially in stream resident females, is much lower in the northern part of their range than that of the anadromous form, and that the opposite may occur in the southern part. The relative fitness of both forms will be shown as in Fig.2.

Figure 3 provides a summary of the hypothesized fitness of fluvial and anadromous life histories relative to each other across their geographical range. Populations existing north of $\mathrm{L}^{*}$ (Fig. 2) receive greater fitness advantages from the anadromous life history (a in Fig. 3) while those south of $L^{*}$ receive greater fitness advantage from the fluvial life history (c in Fig. 3). Populations existing near L* (b in Fig. 3) might adopt: (1) either life history depending upon local food cost such as stream productivity or predation pressure, or (2) mix of the alternative life histories depending upon the differential costs and benefits to specific individuals within a population. For instance, larger individuals within a population may derive less residual fitness benefit from growth in

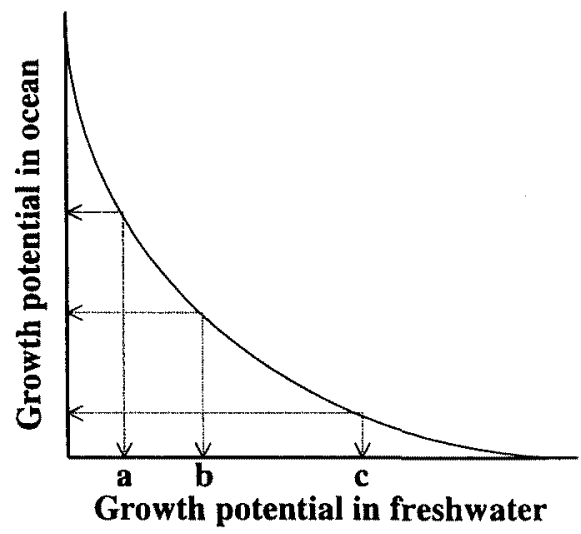

Fig. 3 Graphic model of fitness of fluvial and anadromous life histories across their geographical range. This shows possible relationships between growth potential in ocean and freshwater. a (the former<the latter): only fluvial life history, $b$ (the former=the latter): coexistence of fluvial and anadromous life histories, $c$ (the former>the latter): only anadromous life history. 
the sea, while smaller individuals may gain relatively more residual fitness benefit. At this boundary $\left(\mathrm{L}^{*}\right)$ both anadromous and fluvial (both female and male) apparently coexist in streams for $S$ malma in Shiretoko Peninsula, Japan, ${ }^{51,52)}$ for $S$. leucomaenis in Oshima Peninsula Hokkaido Japan, ${ }^{47,53)}$ and for $O$. masou in Tohoku, Honshu, Japan. Kiso pers. com.)

However, there may be some problems with the FAH. Unlike Dolly Varden and white-spotted charr, in Atlantic salmon and brown trout there was no significant relationship between mean adult size and latitude. $^{49,5(1)}$ The difference among salmonid species may be due to a difference of productivity among oceans and/or a difference of migration mode among species.

\section{CONCLUSION}

The mechanism producing the fluvial life history in salmon and trout will be a conditional strategy, due to responses to environmental conditions that are genetically controlled..$^{44,54,55)}$ As shown in previous studies, $44,45,46,47,48)$ the critical or growth-rate threshold, at which an individual makes a decision to become fluvial or migratory, may be selected in response to the difference in their relative fitness between fluvial and migratory forms. In the northern part of the distribution range in some species of salmon or trout, the relative reproductive success of migratory and fluvial females has latitudinal variation (so called geocline); the fluvial is higher at the southern limits of the ranges, and conversely, the migratory have higher fitness at the northern part. Therefore, all members of a population become fluvial where reproductive success of females may not be different between searun and fluvial. A critical threshold will drastically be selected for a minimum size when there is no difference between anadromous and fluvial life history. Probably the difference in productivity between ocean and freshwater is important, affecting on their growth rate. Our hypothesis includes some testable predictions. For example, (1) juvenile growth rate will change throughout a species' distribution, probably due to differences of food abundance, (2) in the region where fluvial and anadromous salmon or trout coexist, fitness of both female life histories may be about equal. Furthermore, (3) we will be able to create the fluvial form from the anadromous one by growth-rate and/or genetic manipulation, and vice versa. These may play an important role in understanding the evolution or persistence of alternative life histories of salmon.

ACKNOWLEDGEMENT
We thank Mart Gross, John Thorpe, Shoichiro Yamamoto and Felicity Huntingford for insightful and critical comments on a previous draft of the manuscript. This research is supported in part by grants (08454246, 106406606, 13874104, 13660171) from the Ministry of Education, Science, Sports and Culture, Japan.

\section{REFERENCES}

1 Baker RR. The evolutionary ecology of animal migration, Hodder and stoughton, London, 1978.

2 Baker RR. Migration, paths through time and space. Hodder and Stoughton, London, 1978.

3 McKeown B A. Fish migration. Croomhelm, 1984.

4 Gross MR. Evolution of diadromy in fishes. Am. Fish. Soc. Symp. 1987;1:14-25.

5 Stearns SC. The evolution of life histories. Oxford University Press, 1992.

6 Myers ES. Usage of anadromous, catadromous and allied terms. Copeia, 1949;1949:89-97.

7 Gross MR. Salmonid breeding behaviour and life history evolution in changing environments. Ecology;1991 72:11801186.

8 Mcdowall RM. Diadromy in fishes migrations between freshwater and marine environments. Croomhelm, 1988.

9 Fleming IA. Reproductive strategies of Atlantic salmon: ecology and evolution. Rev. Fish Biol. Fish. 1996;6:379-416.

10 Quinn TP, Dittman AH. Pacific salmon migrations and homing: mechanism and adaptive significance. Tr. Ecol. Evol. 1990;5:174-177.

11 Jones JW. The salmon. Collins, London, 1959.

12 Balon EK (ed). Charrs: salmonid fishes of the genus Salvelinus, Dr W. Junk Publishers, the Hague, 1980.

13 Johnson L, Burns B. Biology of the arctic charr. University of Manitoba Press, Manitoba, 1984.

14 Kawanabe $H$. Japanese char( $(r(r)) s$ and masu salmon problems: a review. Physiol. Ecol. Jap. Sp. 1988;1:13-24.

15 Mills D. Ecology and management of Atlantic salmon. Chapman and Hall, London, 1989

16 Ricker WE. 'Residual' and kokanee salmon in Cultus Lake. J. Fish. Res. Bd. Can. 1938;4:192-218.

17 Ricker WE. On the origin of kokanee, a fresh-water type of sockeye and kokanee (Oncorhynchus nerka). J. Fish. Res. Bd. Can. 1940;16:897-902.

18 Power $\mathrm{G}$. The evolution of freshwater races of the atlantic salmon (Salmo salar) in Eastern North America. Arctic 1958;11:86-91.

19 Berg OK. The formation of non-anadromous population of Atlantic salmon, Salmo salar, in Europe, J. Fish Biol. 1985;27:805-815.

20 Thorpe JE, Mangel M, Metcalfe NB, Huntingford FA. Modelling the proximate basis of salmonid life-history variation with application to Atlantic salmon, Salmo salar L. Evol. Ecol. 1998;12:581-599.

21 Thorpe JE. Reproductive strategies in Atlantic salmon, Salmo salar L Aquaculture Fish. Manag. 1994;25:77-87.

22 Holcik J, Hensel K, Nieslanik J, Skacel L. The Eurasian huchen Hucho hucho Dr. W. Junk publishers, the Hague, 1988.

23 Stearley RF. Historical ecology of Salmoninae, with special 
reference to Oncorhynchus. In; R. L. Mayden (ed.) Systematics, historical ecology and North American freshwater fishes, Stanford University Press, 1992, pp.622658.

24 Murata S, Takasaki N, Saitoh M, Okada N.Determination of the phylogenetic relationships among Pacific salmonids by using short interspersed elements (SINES) as temporal landmarks of evolution. Proc. National Acad. Sci. USA. 1993;90:6995-6999.

25 Northcote T. Migratory strategies and production in freshwater fishes. in S. D. Gerking (ed.) Ecology of freshwater fish production. Johan Wiley and Sons. New York, . 1978, pp.326-359.

26 Harada Y. Life history evolution of diadromy. in A. Goto, K. Tsukamoto and K. Maekawa (eds) Freshwater fishes migration between river and sea, Tokai University Press Tokyo, 1994, pp. 186-201 (in Japanese).

27 Maekawa k., Nakano S. Latitudinal trend in adult body size of Dolly Varden, with special reference to the food availability hypothesis. Popul. Ecol. (in press)

28 Gross MR., Coleman RM, McDowall RM. Aquatic productivity and the evoluton of diadromous fish migration. Science 1988;239; 1291-1293.

29 Lorenzen CJ. Primary production in the sea. in DH Cushing JJ Walsh (eds) Marine ecology, Blackwell Scientific Oxford, 1970, pp. 173-185.

30 Dodson JJ. Fish migration: an evolutionary perspective. In Godin JJ (ed) Behavioural ecology of teleost fishes, Oxford University Press, Oxford, 1997 pp.10-36.

31 Kawamura $\mathrm{H}$. Freshwater fishes in the eastern Hidaka coast and Cape Erimo in Hokkaido, Japan. Sci. Rep. Hokkaido Fish Hatch. 1982;37:1-12 (in Japanese).

32 Martin NV, Olver CH. The lake charr, Salvelinus namycush. In E. K. Balon (ed) Charrs: salmonid fishes of the genus Salvelinus. Dr W. Junk Publishers, the Hague, 1980 pp.205277.

33 Johnson L. The arctic charr, in U. K. Balon (ed) Charrs: salmonid fishes of the genus Salvelinus, Dr W. Junk Publishers, 1980, pp15-98.

34 Armstong RH, Morrow JE. JE The Dolly Varden charr, Salvelinus Malma, In E. K. Balon (ed) Charrs: salmonid fishes of the genus Salvelinus. Dr W. Junk Publishers, the Hague, 1980, pp.99-140.

35 Fausch KD, Nakano S, Ishigaki K. Distribution of congeneric charrs in streams of Hokkaido Island, Japan: considering multiple factors across scales, Oecologia 1994;100:1-12.

36 Power G. The brook charr, in U. K. Balon (ed) Charrs: salmonid fishes of the genus Salvelinus, Dr W. Junk Publishers, the Hague, 1980, pp.141-203.

37 Groot C, Margolis L. Pacific salmon life history. UBC Press, Vancouver, 1991.

38 L'Abee-Lund JH, Jensen AJ, Johnsen BO. Interpopulation variation in male parr maturation of anadromous brown trout (Salmo trutta) in Norway. Can. J. Zool. 1989;68:1983- 1987.

39 Kimura S. The Yamame, land-locked masu salmon of Kyushu Island, Japan. Physiol. Ecol. Jap.1989;1;77-92. (in Japanese).

40 Nakano S, Kitano F, Maekawa K. Potential fragmentation and loss of thermal habitats for charrs in the Japanese Archipelago due to climatic warming. Freshwater Biol. 1996;36:101-112.

41 Armstrong RH. Migration of anadromous dolly varden (Salvelinus malma) in southeastern Alaska. J.Fish. Res. Bd. Can. 1974;31:435-444.

42 Gritsenko OF, churikov AA. The biology of chars (genus Salvelinus) and their place in the ichthyocoenoses of bats in the northeastern Sakhalin 1. Migration, age, growth and maturation. J. Ichthyol. 1976 15:921-930.

43 Blackett RF. Fecundity of resident and anadromous dolly varden Salvelinus malma (Walbaum) in southeastern Alaska. J. Fish. Res. Bd. Can. 1973;30:543-548.

44 Thorpe JE. Smolting versus residency: developmental conflict in salmonids. Am. Fish. Soc. Symp. 1987;1:244252.

45 Gross MR. Alternative reproductive strategies and tactics: diversity within sexes. Tr. Ecol. Evol. 1996;11:92-98.

46 Hutchings JA, Myers RM. The evolution of alternative mating strategies in variable environments. Evol. Ecol. 1994;8:256-268.

47 Yamamoto S, Morita K, Goto A. Geographic variations in life histories characteristics of white-spotted charr (Salvelinus leucomaenis) Can. J. Zool. 1999;77:871-878.

48 Okland F, Jonsson B, Jensen AJ, Hansen LP. Is there a threshold size regulating seaward migration of brown trout and Atlntic salmon? J. Fish Biol. 1993;42:541-550.

49 Metcalfe NB, Thorpe JE. Determinant of geographical variation in the age of seaward-migration salmon, Salmo salar. J. Anim. Ecol. 1990;59:135-145.

50 Jonsson B. L'Abee-Lund JH. Latitudinal clines in lifehistory variables of anadromous brown trout in Europe. $J$. Fish Biol. 1993;43: 1-16.

51 Maekawa $\mathrm{K}$. Occurrence of stream resident females in Miyabe charr. Japan. J. Ichthyol. 1989;36:141-143.

52 Komiyama E, Ohtaishi N, Maekawa K. Occurrence of a sea-run type of the Dolly Varden in the Shiretoko Peninsula, Hokkaido. Japan. J. Ichthyol. 1982;29:298-302.

53 Yamamoto S, Takahashi Y, Kitano S, Goto A. Residual female parr in an anadromous population of white-spotted charr, Salvelinus leucomaenus, in southern Hokkaido, Japan. Japan. J. Ichthyol. 1996;43:101

54 Jonsson B. Diadromous and resident trout Salmo trutta: is their difference due to genetics? Oikos 1982;38:297-300.

55 Thorpe JE. Age at first maturity in atlantic salmon Salmo salar: fresh water period influences and conflicts with smolting. Can. Sp. Pub. Fish. Aqut. Sci. 1986;89:7-14. 